\title{
From the Unity of the World to God: A Teleo-Cosmological Argument for God's Existence
}

\author{
PAULO JUAREZ \\ Independent Research, USA \\ pj2205@hotmail.com
}

\begin{abstract}
In this paper I pursue an avenue of argument implicit in Patristic thinkers - such as Tertullian and Athanasius - and explicit in the thomistic and scholastic tradition. I argue that there is an ontological unity to the world, and that this unity calls for an explanation in terms of a transcendent cause, traditionally identified with God.
\end{abstract}

Keywords: universe; cosmos; natural theology; metaphysics; order.

For we find all existing things to be in mutual order, some of them subordinate to others. But things that are diverse combine in a single order only where there is a single cause of order. For unity and order is introduced into a plurality of things more perfectly by a single cause than by many, for unity produces unity intrinsically, while the many produce unity only incidentally and in so far as they are also somehow one. Since therefore what is first is most perfect, and is so essentially and not incidentally, it must be that the first which reduces all into one order should be only one. And this is God. - Thomas Aquinas 


\section{Introduction}

There are many words by which we refer to the whole of physical reality:

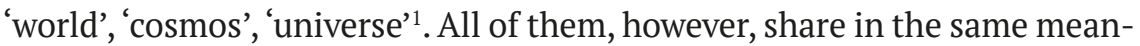
ing: a unity of many things. The world is comprised of a great diversity of beings, each existing in itself and not as part of any other being; and yet the world is, in some sense, one. This unity is an ontological feature of our universe, and as such calls for an explanation.

We may begin by distinguishing between two kinds of unity: per se (or substantial) unity and per accidens (or relational) unity. The first kind of unity refers to the unity enjoyed by substances. Consider a human. We understand intuitively that a 'human' refers to something over and above his or her individual parts as parts. A human is not a disarray of parts, but a 'whole', a substance to which all its individual parts are ordered. Now consider the world. It seems clear that the world is not one, the way a human is one - there is not one homogenous substance we call 'the world'2. There is, however, a relational unity to the world, such that its many and diverse component elements are united so as to form a single objectively existing and visible order, a whole of sorts, a non-substantial system. There is thus a distinction "between substantial [unities] which are absolute unities, unum

I will be using these words interchangeably throughout this paper.

2 That the world is not a unity in a substantial sense may be obvious in the context of Western philosophy: the world just is the totality of physical reality. This is perhaps not so obvious in the context of Eastern philosophy. In response, we may express a worry shared by Leibniz, namely, that it is difficult to see how any relation of substances, distinct and uncompromised by the relation formed, could ever amount to a substantial unity. Such a relation would still be a relation of distinct things, such that they could not amount to one thing in the strict sense of the word. According to Leibniz: "Nothing will ever be found fitted to constitute a true substance out of several beings by means of aggregation; for example, if the parts which fit together for a common design are more appropriate to constitute a true substance than those which are in contact, all the officials of the India Company in Holland would constitute a real substance better than would a pile of stones. But such a common design-what is it but a resemblance, or rather an arrangement of actions and passions, which our mind sees in different things? If unity by contact should be preferred as the most reasonable hypothesis, other difficulties would be found: the parts of solid bodies are perhaps united only by the pressure of surrounding bodies and by their own pressure, and in their substance they may have no more union than a pile of sand." (Emphasis mine) (Montgomery 1980). 
simpliciter, for example, those that are composed of matter and form, and unities and wholes secundum quid, in which a real plurality forms a unit by juxtaposition or interrelation and in which the parts do not completely lose their autonomy." (Meyer 1944) The unity of the world falls into this latter kind.

How do we come to know that there is a unity to the world? According to one reading of Kant, an argument is to be made that the unity of the world is presupposed or given to us a priori in conscious experience. According to P.F. Strawson, the following argument can be found in Kant's B-Deduction, $\S \S 15-20$ : "the fact that my experience is of a unified objective world is a necessary consequence of the fact that only under this condition could I be conscious of my diverse experiences as one and all my own" (Strawson 1975). In other words, just as the very possibility of conscious experience presupposes that there must be a unity of consciousness - the "I" that accompanies all of our representations - so this unity of consciousness presupposes that there must be a unity of the laws according to which we experience the world. The unity of consciousness thus presupposes the unity of the world.

As an exegetical argument, it is worth noting that Kant scholars differ in their interpretation of this controversial text. According to a different interpretation, Kant's project is not to show that the unity of the world is a mere representation or product of our self-consciousness, but rather to show that skepticism about the external world is mistaken: if the unity of conscious experience demands a unified, objective world, then such a world would be a priori necessary. This reading, however, is unorthodox, so let us grant Strawson's reading for the sake of argument. It is not altogether clear that Kant's argument aids us in understanding the unity of the world. For the argument would only serve to show that the world is given to us as a unity in the order of knowledge; it would remain a matter of demonstration whether the world is a unity at the ontological level. Moreover, the argument appears to give rise to a certain skepticism regarding our ability to know objective principles of reality as objective. For if the world is given to us as a unity in our conscious experience - in the order of knowledge, but not in the order of ontology - why not simply say that the unity of the world is 'of our own making', as it were? In Kantian terms, perhaps the world is 
a unity in the order of phenomena - the way things are for us - but not in the order of noumena - the way things are in themselves.

What we need, then, is to move beyond any inward analysis of conscious experience, and to look outwardly, to the world as it is, if we are to understand the unity of the world. And here we are presented with an ordered system of many component elements, all of which interact with one another in regular, reciprocal relationships we understand as physical laws. W. Norris Clarke offers the following account:

[A]ll hydrogen atoms are ordered toward combination with all oxygen atoms in the fixed proportion of 2 to 1 , whereas all oxygen atoms are in turn ordered towards all hydrogen atoms in the reciprocal proportion of 1 to 2 , to form water (H2O); the same holds for the fixed chemical valences of all atoms, the mutual gravitational attraction of all particles in the universe with mass, the strong force holding together the particles in the nucleus of atoms, electromagnetic laws, and so on - all of these laws combining to form a unified cosmos-wide order. (Clarke 1995)

Franz Brentano points to the interrelationship between the inorganic realm and the organic realm, such that "if any of the essential, or even quite accidental properties of the inorganic world is altered, the living things can neither continue to exist nor carry out their principal functions" (Brentano 2011/1987). Here we have a unity-in-diversity, that is, "a unity in the interrelation of forces and capacities, such that one provides what another requires for its operation, and they complement one another as it were." (Brentano 2011/1987)

Consider further the way life hinges on certain relationships between the fundamental physical constants; or the way dark matter interacts with ordinary matter and gravity so as to contribute to the creation of galaxies, which in turn contributes to the creation of stars, which in turn contributes to the creation of heavier nuclei, which finally contributes to the creation of human beings. The unity of the world, then, consists in the synchronic and diachronic interrelations of its many diverse elements, such that each part exists and is intelligible relative to one another, and relative 


\section{to the whole - the world-system - to which they contribute, and by which they are determined ${ }^{3}$.}

But why suppose that the parts of the world, while dependent upon one another for their existence and operations, further depend upon a greater relational whole? Consider that if the world is such that the existence and nature of each active element stands relative to another, then no one element can fundamentally account for its own existence and nature. In such a system, no one element can be "the sufficient reason for its own active nature as existing and operating, unless it is also the sufficient reason for all the others reciprocally related to it" (Clarke 1995), which is impossible. As their distinct and sufficient reason, such an element would have to be both causally and logically prior to them so as to account for their distinct natures. But, as has been noted, the existence and nature of each element in the world is defined by its relation to other elements, such that all elements presuppose one another for their distinct intelligibility and activity. Every active element thus contributes to, yet is comprised by, a cosmos-wide unity or system.

Let us cast the above argument in a more formalized light:

1) The existence and activity of every being within the world depends, at every moment, upon their relative standing to other beings.

2) These interrelations among beings, substantially one and distinct one from another, form a complex, hierarchical ordering, such that the beings of our experience depend upon, and are related to, deeper and deeper levels of reality. Ultimately, these beings are typically

3 According to Thomas Aquinas, the unity of the world - the world as cosmos - consists in the ordering of its parts relative to one another. Taken collectively, the 'parts' of the universe, in all their diversity, constitute a per accidens (or relational) unity, what Aquinas would have understood as an accidental form. Aquinas notes, however, that the 'parts' of the universe and the unity or 'form' to which they belong are both essential components: they go hand in hand, neither reducible to the other. He adds: "it is through [its form] that the universe is constituted in its totality." (Kretzmann 2002) In other words, the unity of the world is not simply reducible to its component parts. On the contrary, it is the world's unity that fundamentally "makes possible the flourishing of any particularly impressive smaller-scale component of it." (Kretzmann 2002) The 'parts' of the world may be logically prior to the unity they constitute, but it is by virtue of this unity that the parts of the world exist at all. 
said to be governed by certain physical forces, themselves possibly governed by a single, quantized force ${ }^{4}$.

3) This complex, hierarchical ordering of beings, one dependent upon another, constitutes a unity or a system.

4) This greater unity or system is not reducible to the parts of the world, but belongs properly to the world as a whole.

$\therefore$ The universe is a unified whole ${ }^{5}$, a system.

\section{The need for explanation}

The unity of the world calls for an explanation. As we have seen, such explanation cannot be found in the elements that make up the world. For there is no one member, so far as it is part of a greater whole, that can account for the unity of the whole as such. Moreover, it is difficult to see how the myriad elements that make up the world could, by virtue of their multiplicity and diversity, account for the unity of the world as a whole.

The world as a whole cannot explain its own unity, either. As we have already noted, the world is not a separate being, existing independently of its active parts. There is not one substance we call 'the world', such that its

4 Many physicists have sought to unify the most fundamental constituents of the universe under a single, unified theoretical framework according to which the known elementary particles, the four fundamental forces - gravitational, electromagnetic, strong nuclear and weak nuclear - together with data concerning the evolution of the universe are hierarchically ordered under a single, quantized force. This search for a Theory of Everything (ToE) is one of the major unsolved problems in physics, and finds its echo in the pursuit of many Greek philosophers for a First Principle of all things. Here the physicist and the classical philosopher appear to be of one voice. To be sure, no ToE has been forthcoming; but the very search takes for granted that there is a unity to the world, an assumption that is intelligible only in light of the interrelatedness among substances, and their hierarchical dependence on deeper and more fundamental levels of reality, as contemporary physics reveals.

5 Recall that by a 'unified whole', I do not mean that the world is a substantial whole. As I have suggested, the world is a 'whole' so far as it is a relational whole, analogous to a system. Clarke defines a system as "a set of relations forming a new unified order... which has its own set of properties as a system and influences its members accordingly." Metaphysically speaking, the concept of a system "deserves recognition as a distinctive mode of real being between the autonomous self-existing being of substance and a mere aggregate of external, superficial relations. Hence it belongs to the order of accidents, but is a unique kind of accident that inheres in many subjects at once.” (Clarke 2001). 
unity belongs to it intrinsically; thus, the unity of the world is accidental (or relational), and thus not intrinsic to it.

Could the unity of the world be explained in terms of the laws of physics? It could not, for the laws of physics are not concrete so as to cause anything. Indeed, as I will argue, there is no plausible account according to which the laws of physics can be said to be efficacious in the required sense.

A 'law' in the scientific sense is typically understood as an expression of the observable relationships between measured quantities, confirmed by many (or few) experiments, and codified into an algebraic equation. This is true enough; but it doesn't go very far in giving credence to the idea that the laws of nature are causally efficacious. Indeed, it would remain a matter of demonstration whether and how the laws of nature could be said to causally explain anything, and how they could do so without themselves requiring an explanation. What we need to get clear on, then, is just what the laws of nature are supposed to be at their most fundamental. Are they merely statements to the effect that 'events of type A are regularly followed by events of type B'? Are they entities in themselves, in which the world participates in a Platonic sense? Are they merely a shorthand account for how something will tend to behave given its nature or essence?

According to a 'Regularist' theory of the laws of nature, laws of nature are statements to the effect that A's are "always accompanied (or preceded or succeeded)" (Russell 2007) by B's. On this analysis the laws are simply descriptive of the patterns of regularity found in nature; they do not causally explain why these patterns exist, let alone why the physical objects and systems which exhibit them exist. By parity of reasoning, suppose every law of nature to be reducible to some grand, unifying law. Such a law could only describe the unity of the world; it could not be causally responsible for it.

According to a 'Platonic' theory of the laws of nature, laws of nature are concrete entities in themselves, akin to Platonic forms, and the elements of the world behave and appear as they do so far as they participate in these forms. This is a more plausible candidate, since, being concrete, the laws of nature could be said to causally account for the unity of the world by way of participation. But this theory's explanatory power is quickly overshadowed 
by a number of difficulties. Just how is it that the world comes to participate in the forms that it does? And why is it that it participates in these particular forms (laws), rather than others? On a Platonic account, the laws of nature are simply not the end of the story, and so they cannot serve as the ultimate explanation of the world's unity.

According to an Aristotelian theory of the laws of nature, the laws are just shorthand for how a natural substance will tend to behave given its nature or essence. Here a similar objection to the Regularist account just considered holds: what is it about an Aristotelian conception of the laws of nature that entails their causal efficacy? The laws merely describe the behavior of natural substances; they do not account for it.

Finally, one may argue, echoing the work of Nancy Cartwright (Cartwright 1999) and others (Cartwright \& Ward 2016) that what makes up the furniture of the world is not laws, but powers. The order and regularity we find in the world is grounded in the causal powers of substances rather than laws - ceteribus paribus, phenomenological, or causal. According to this account, quarks behave as they do, not by virtue of some law, but rather because of certain inherent causal powers, themselves dependent upon the causal powers of other substances - such as nucleons and the forces that obtain from their interactions. This Aristotelian and Neo-Aristotelian understanding of powers has gained some prominence in recent years (Mumford \& Anjum 2015; Greco \& Groff 2017; Marmodoro 2013; Molnar 2007.) Moreover, if correct, it would serve to reinforce the major premise of our argument, namely, that there is an interdependence among substances which contributes to our understanding of the world as a unified whole.

Might the unity of the world be simply a brute fact about its constitution? That of course depends on what is meant by a 'brute fact'. If by a brute fact one has in mind something for which we simply refuse to give an explanation, then it seems that in principle we could make of any fact a brute fact, either by remaining silent, or by simply arriving at an arbitrary point in our explanation and saying nothing further. Here a brute fact turns out to be more of a dismissal, a shrugging of the shoulders, than a genuine metaphysical stopping point. Surely it will not do to say that the unity of 
the world is a brute fact in this sense, for it is simply contrary to the spirit of metaphysical inquiry to seek to rest any explanation on the unexplained or the inexplicable. To be sure, it may be the case that some explanations can only be pushed so far; but there is a difference between looking to a brute fact as an explanans, and genuinely arriving at an axiomatic stopping point within a given domain, or even arriving at some explanans that does not assume the existence of the explanandum. This latter sense of a 'brute fact' is no doubt more reputable than the former, but it is not the sort of predication that could be reasonably made of the universe in toto, at least not without argumentation or in the presence of some putative explanation for why the universe is a unified whole ${ }^{6}$. Finally, if we are prepared to dismiss the unity of the world as a brute fact, then we should be equally prepared to dismiss the more specific and particular unified arrangements within the world - such as the interrelationships between the inorganic and the organic, the macro world and the micro world, and so on - as brute facts. Of course, we do take these relationships of reciprocity to obtain by virtue of some cause or nexus

6 Suppose two people are trying to account for the existence of some phenomena P. One person offers a putative explanation E, while the other person simply asserts that, for all we know, the existence of $\mathrm{P}$ is just a brute fact, without explanation. The problem, of course, is that this person has just been given a putative explanation for why P exists, and so it is no good simply to claim, on the basis of alleged epistemological ignorance, that perhaps there is no explanation for why $\mathrm{P}$ exists, or worse, that there could not in principle be an explanation for why $\mathrm{P}$ exists. Formalized, this argument runs thus:

1) If appeals to brute facts are ever justifiable, then they are justifiable only in cases where there is in principle no possibility of explanation.

2) There is a possible explanation $E$ for the existence of $P$.

3) Hence, it is not justifiable to appeal to a brute fact as an explanation of $\mathrm{P}$.

What if the putative explanation E seems so implausible to a person that she thinks reference to a brute fact is more preferable? Such an objection runs the risk of confusing the order of priority between the epistemic and the ontological. In other words, it seems problematic to appeal to one's personal, epistemic state as the determining reason for exempting $\mathrm{P}$ from causal explanation. Perhaps the putative explanation $\mathrm{E}$ is implausible; but that is an argument in favor of some other explanation, before it is an argument for the intrinsic inexplicability of P. The objector may instead point to the unstated presumption that there must always be some logically possible explanation for things or states of affairs. This 'presumption', however, is a fine one, underlying the very basis of empirical science. Moreover, it is grounded upon a philosophical principle dating back to the beginnings of philosophy: the Principle of Sufficient Reason (or PSR). For a sustained defense of the PSR, see Della Rocca 2010, Pruss 2010, and Feser 2014. 
of causes, so one may question why the world, considered as the system or unified whole to which these parts are ordered - and by which they are influenced - should somehow be exempt from explanation.

\section{The argument}

As I have argued, there is an ontological unity to the world: all the parts of the world are interrelated in such a way that no part could exist, or behave as it does, apart from the existence and operations of the other parts. Every part is correlative one to the other, and in their totality they constitute, and are constituted by, the world as a unified whole. Following Aquinas, I will argue that, if the world exhibits such an ontological unity, then there must be a principle of unity, some unitary cause, behind it. Perhaps the clearest formulations of such an argument can be found in Summa Theologiae, First Part, Question 11, Article 3, and Summa Contra Gentiles, Book III, Chapter 64, Article 6.

Summa Theologiae, First Part, Question 11, Article 3:

For all things that exist are seen to be ordered to each other since some serve others. But things that are diverse do not harmonize in the same order, unless they are ordered thereto by one. For many are reduced into one order by one better than by many: because one is the [essential] cause of one, and many are only the accidental cause of one, inasmuch as they are in some way one. (Emphasis mine)

Summa Contra Gentiles, Book III, Chapter 64, Article 6:

Furthermore, things that are different in their natures do not come together into one order unless they are gathered into a unit by one ordering agent. But in the whole of reality things are distinct and possessed of contrary natures; yet all come together in one order, and while some things make use of the actions of others, some are also helped or commanded by others. Therefore, there must be one orderer and governor of the whole of things. (Emphasis mine)

For Aquinas, the unity of a multitude cannot be explained without recourse to some outside, unitary principle, by which diverse things are 'gathered' into 
a single order or mode of operation. In other words, a multitude as such cannot be the cause of its own unity. This could be interpreted as an expression of the principle of proportionate causality, which states, roughly, that no cause can give what it does not itself have - and, a fortiori, that any effect must first pre-exist, in some form or other, in the cause. In other words, the unity present in an effect - in this case, the unity of the world - must first exist in some cause capable of imparting such unity. Moreover, since the unity of the world cannot be explained in terms of its members, the principle or cause of the unity of the world cannot reside within the world, but must be extrinsic to it. Hence, there must be an extrinsic cause or principle responsible for the diverse elements of the world coming together into one unity, one cosmos.

Consider a second argument. I have suggested that the world might be best understood as being analogous to a system. By a 'system' I have in mind any type of "unified immanent order which [links] together groups of individuals in such a way that they form a single objectively existing and recognizable order, a single intelligible network or pattern of relations forming a whole" (Clarke 2009). Examples of systems with which we are familiar are: systems of particles, atoms, and molecules; ecological systems of plants and animals; systems of stars and galaxies; and so on. In most cases a system is non-substantial, that is, not a whole as such, and yet its existence is so important that "the members or elements it integrates can neither exist, nor act, nor be understood in their essential intelligibility except in function of the unity of the system as a whole." (Clarke 2009)

I have argued that the world is a system in this precise sense. So understood, the many constituents of the world are neither self-sufficient - since their existence and operations are always relative to other component parts or elements - nor self-explanatory - since no part of a system is intelligible apart from the whole. One must therefore posit a transcendent principle of unity, a unifying efficient cause, to account for the unity of the world.

A third argument is drawn from Athanasius of Alexandria, a third-century church father. In his work On the Incarnation, he argues as follows:

[I]f everything has its beginning of itself, and independently of purpose, it follows that everything would only exist, so as to be alike and not distinct. And, given that 
body is homogeneous, it would follow that everything must be sun or moon, or that a man would be only a hand, or eye, or foot. But as it is this is not so; rather, we see a distinction of sun, moon, and earth; and again, in the case of human bodies, of foot, hand, and head. Now, such arrangement of separate things as this tells us not of their having come into being of themselves, but shows that a cause preceded them; namely God, the one who makes and orders all. (Athanasius 2012)

As I see it, the major premise in Athanasius' argument is:

1) Where diverse elements form a single reality, there must be some cause separate from them. (Chastek 2013)

Consider the scattered pieces of a puzzle, coming together to form a single whole; or both leg bone and muscle fibers, enjoined by the tendon so as to produce movement; or matter and form, coming together so as to constitute one substance. The major premise thus seems fairly plausible. Now recall that the diverse elements of the world both constitute and participate in an ontological unity we call 'universe' or 'cosmos'. We thus have an argument for a transcendent cause of the universe as a single reality:

1) Where diverse elements form a single reality, there must be some cause separate from them.

2) The diverse elements of the world form a single reality, a 'universe' or 'cosmos'.

3) Hence, there must be a cause, separate from the diverse elements of the world, and responsible for their forming a single reality.

In defense of 3, consider that if the cause of the universe as a single reality or unity were immanent to the universe, then it would be a mere part of the system that is to be explained. (This is another reason why appeals to the laws of nature are inadequate - as if the laws of nature could at once be both immanent and transcendent, pervading all things while somehow being separate from them.)

A fourth argument may be drawn from the kind of interconnectedness and interdependence that characterizes the unity of the world. As I have argued, the unity of the world consists, not only in the diachronic interrelations of varied substances, but also in their synchronic interrelations, such that the being and nature of one kind of substance is defined relative 
to its acting upon - and being acted upon - another kind of substance. Indeed, as I will argue, the unity of the world is fundamentally synchronic, such that every substance is radically dependent upon other substances, not primarily in a temporal sense, but in a hierarchical sense - at a single moment of time, as it were.

Consider a diachronic series of events such as the following:

T1 The universe comes into existence

T2 The universe begins a process of expansion and evolution at the moment of the big bang, and with it the conditions necessary to sustain life on earth.

T3 The first unicellular organism arrives at the scene

T4 From this organism spring forth, over the course of millions of years, a wide array of ever more complex lifeforms.

T5 This evolutionary process culminates in the arrival of man.

We need not quibble over the finer details of this account to grasp the general character of such a series: one event takes place at T1, another event takes place at T2, and so on, in a linear sequence. There is an obvious sense in which the later events are absolutely dependent upon the earlier events for their existence - no man would exist, here and now, in the absence of the evolutionary process described at $\mathrm{T} 4$, and the first unicellular organism at T3. Certainly no event would exist today, had T1 failed to obtain! But this sense of dependency is one-way, and does not reflect the kind of immediate dependence upon other substances that characterizes the unity of the world. Though the arrival of man did depend upon the universe having come into existence at $\mathrm{T} 1$ - at the Big Bang, say - the Big Bang is not here and now required to explain the existence of man as presently existing; the Big Bang was an event long buried in the past; yet, I presently exist. Consider another example: does man presently depend, for his existence and operations, upon the existence of those prior lifeforms - those currently existing, as well as those now extinct - that favored his coming to be? Surely not. Hence, the sense of dependency one finds in diachronic series of events is quite different from the immediate dependency of one substance upon another that characterizes the world as a unified whole. 
Consider now man outside the context of a diachronic order. Man is an intelligent lifeform, a lifeform that depends, in an immediate sense, upon multicellular life for his existence and operations. Similarly, all multicellular life depends, here and now, upon an immediate standing to eukaryotes, eukaryotes to prokaryotes, prokaryotes to protocells, protocells to proteins and DNA/RNA; and so on and on. Every member in this series is radically dependent upon one another, such that no member could exist, and be the kind of thing that it is, apart from those members upon which it depends. We may say that this relation of dependency is vertical, rather than horizontal:

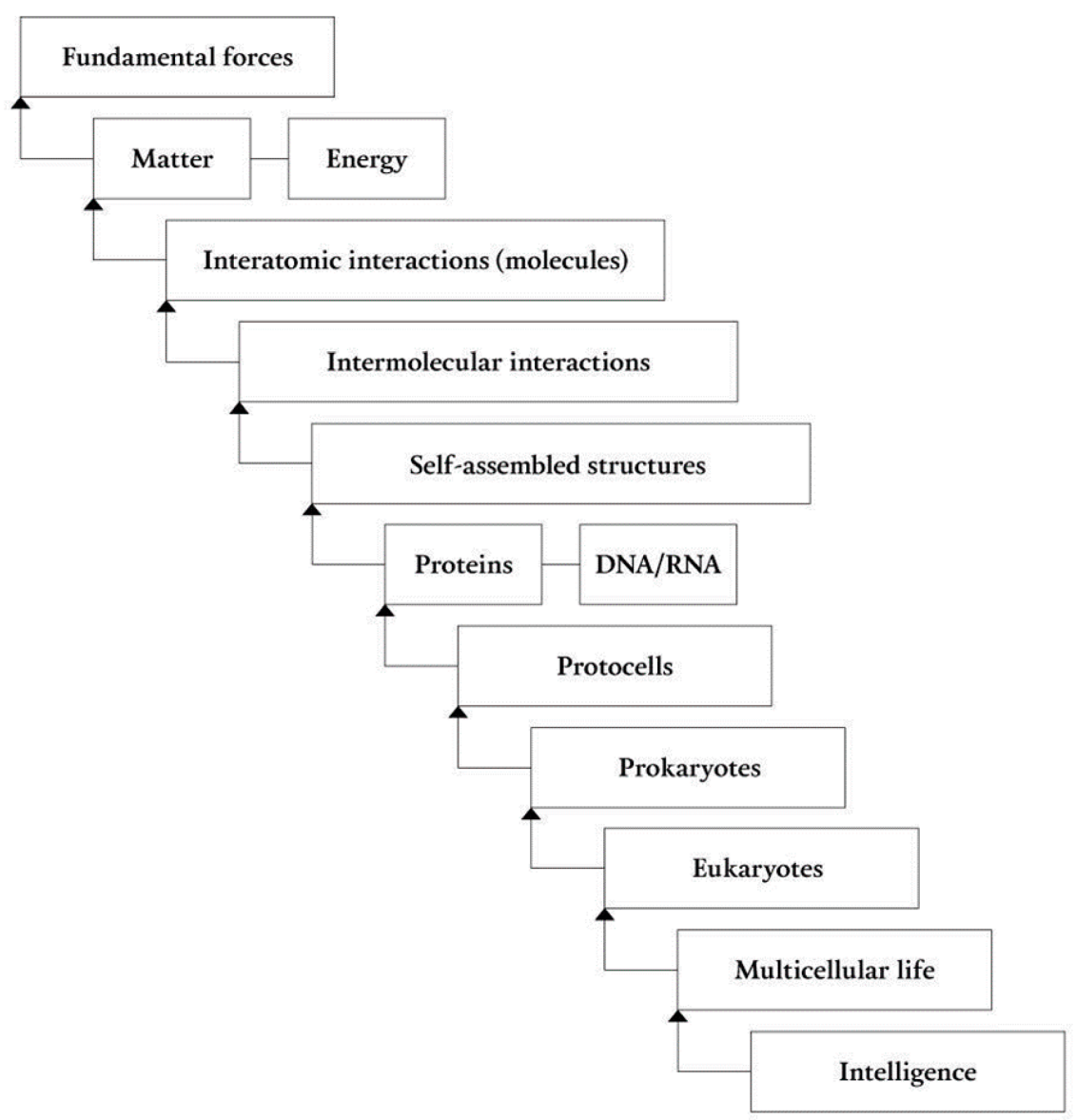


Consider a broader example. The being and operations of any lifeform depend, here and now, upon the being and operations of planets, which depend, here and now, upon the being and operations of heavier nuclei, which depend, here and now, upon the being and operations of stars, which depend, here and now, upon the being and operations of nebulae, which depend, here and now, upon the being and operations of dark and ordinary matter; and so on and on:

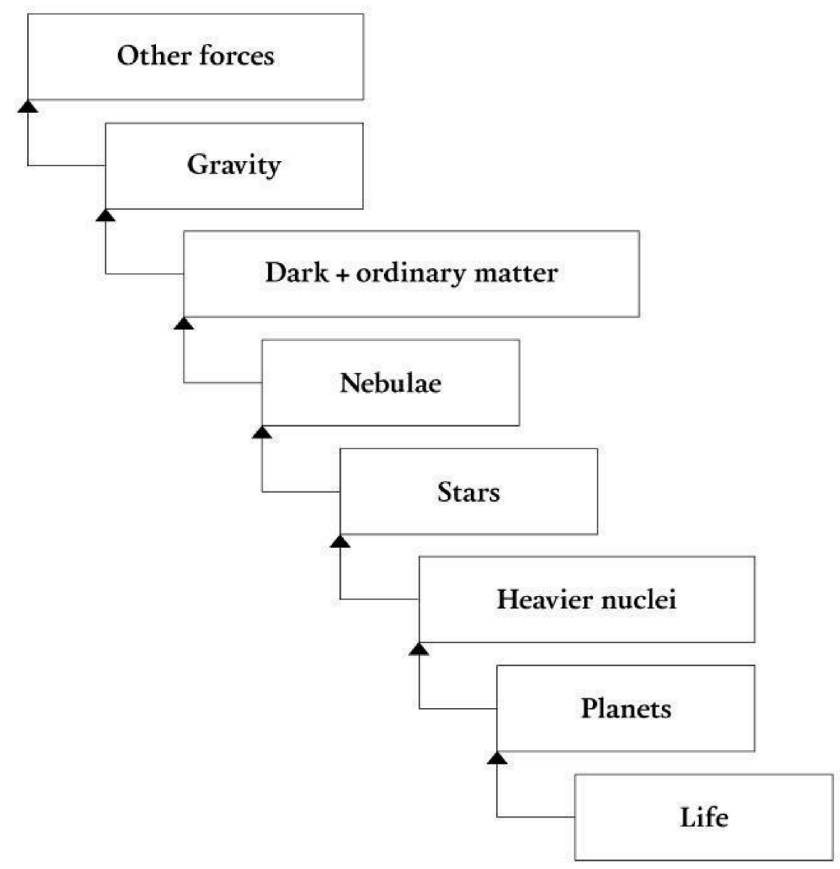

In these examples we find two series in which the dependence of one member upon another plays out, not temporally, but hierarchically, at a single moment of time. Again, this relationship of dependence is not horizontal or linear, but vertical. These examples constitute what we would call a synchronic series of members and events. The importance of this in the context of my argument is, I hope, clear: if the unity of the world consists in 
the interconnectedness and interdependence of one kind of substance upon another kind of substance, then the character of this unity is fundamentally synchronic, since in a diachronic series the later members can exist and operate independently from the prior members within the series. Indeed, for any diachronic series of members and events, it seems reasonable to hold that, either the series itself, or part of the series, will be fundamentally governed by, or subordinated to, some synchronic series of members or events. Put differently, for any diachronic series $P$, either $P$, or part of $P$, will be fundamentally governed by some synchronic series $M$.

Consider now that in any synchronic series of members, the interrelatedness and interdependence of one member upon another is such that every member within the series possesses being only in a derivative or 'borrowed' way. Organisms are not self-existent, but dependent upon cells and their structure; cells and their structures are not self-existent, but dependent upon super-molecular interactions; and so on and on. Every member within a synchronic series owes its power to be, and to act as the kind of thing that it is, to more fundamental, logically-prior members, themselves dependent for their power to be, and to act as the kind of thing that they are, to more fundamental members still; and so on and on. The question arises: how far can this series extend? To infinity?

Consider by analogy a book, which owes its existence to a copy of the book, which owes its existence to a further copy of the book, and so on to infinity. In terms of explanatory power, this is surely problematic. For how could any books exist, without there being some fundamental, non-derivative cause of the book and its copies, i.e. an author? But now consider any possible synchronic series of causes where a) every member has its power to be and to act from another member; where b) every member in the series is essential - such that they could not be removed without impacting the existence of the other members; and c) where this act of dependency is immediate. If such a series extended to infinity - one member dependent upon another (logically-prior) member, itself dependent upon another (logically-prior) member, and so on and on - then ultimately the being and causality of every member within the series would be unintelligible, since 
no member could fundamentally account for the existence of all the others. That which possesses existential and causal power only in a derivative sense cannot be explained, in any ultimate sense, by recourse to something of the same derivative character. That is one problem. But there is a more pernicious problem: were an infinite series of synchronic causes possible, and were this series such that no member fundamentally accounted for the existence of all the others, then no member would, here and now, exist. Per absurdum, no series of synchronic causes can extend to infinity, but must terminate in some non-derivative or primary source, from which every member within the series fundamentally derives its being and causality.

We can now apply this conclusion to the totality of synchronic causes. If the radical interconnectedness and interdependence of every member upon another - the unity of the world - is of a fundamentally synchronic character, then there must exist some primary, non-derivative source, responsible for the being and causality of every member within the world. Such a being would be the fundamental, non-derivative cause of the unity of the world.

\section{Attributes}

We have concluded, by way of four varied arguments, that there is a transcendent cause, a principle of unity, responsible for the creation and upholding of the unity of the world. But what must such a cause be like? Consider that, qua transcendent, the unifying efficient cause of the world must reside 'outside' spatio-temporal reality. This cause must thus be non-spatial - and hence immaterial - as well as timeless. The unifying cause of the world must also be extremely powerful, responsible as it is for the ordering and sustaining of a wide diversity of substances into a unified whole.

This principle of unity must be non-composite, and therefore simple. Robert Koons offers an intriguing argument for this conclusion:

Any composite entity involves coincidences: correlated relations among the parts and the whole. Suppose, for example, that some entity X contains two 
proper parts, Y and Z. Given the mereological principle of Companionship, the fact that $\mathrm{Y}$ is a proper part of $\mathrm{X}$ entails that $\mathrm{X}$ has some other proper part, and, similarly, the fact that $Z$ is a proper part of $X$ entails that $X$ has some other proper part. The [ultimate] causal explanation of these coincidences cannot be a composite entity, since the unexplained unity of the cause would render it incapable of explaining the unity of its effect. Hence, we can infer the existence of at least one absolutely simple cause of the unity of [the world]. (Koons, 2016)

As we have argued, however, the principle of unity of the world must be immaterial, and so its simplicity could only be predicated of its metaphysical parts. The principle of unity of the world is thus metaphysically simple. We can then ask whether in such a being there can be a distinction between its essence and its existence, neither of which entail the other. I can conceive of what a thing is, independently of whether it is. We can say, for example, that the essence of a unicorn is to be a horned creature resembling a horse; but it is not of the essence of such a creature to exist. It follows that if the principle of unity of the world is metaphysically simple, then there can be no distinction between essence and existence, such that its essence just is its existence.

Now, for any concrete being in which essence and existence are distinct, both essence and existence must be 'conjoined' or brought together by some extrinsic cause. Cats, trees, cars, galaxies, photons - as essence/existence composites, it is not within the essence of any of these things to exist, and hence they do not possess within themselves the reason for their existence. But anything that does not possess within itself the reason for its existence must owe its existence to some extrinsic cause. Hence, to be an essence/ existence composite is to be contingent, that is, to possess existence only in a derivative way. Recall now that the cause of the unity of the world is metaphysically simple, such that its essence is identical with its existence. Such a cause must thus be metaphysically necessary, such that it cannot, even in principle, owe its existence to anything else.

The principle of unity of the world must plausibly be a unifying mind. For consider that this principle - this immaterial principle - is causally responsible for "gathering many different elements into an intelligible unity 
that is system-wide, yet without collapsing together the real distinctness and separation in space and time of each element." (Clarke 1995) Now the bringing together of many elements into one unity, without destroying the integrity and distinction of every element, "is almost a definition of an idea. And an idea must originate from a mind." (Clarke 1995) Plausibly, then, the principle of unity of the world is a mind.

Consider a second argument. The gathering of all the elements of the world into a unified whole contribute to a precise degree of order and harmony, such that the world can be said, in its totality and its multiple proportions exemplified by the laws of nature, to possess a certain aesthetic quality. As Hans Mayer notes, "everything that is ordered has the mark of beauty in it." (Meyer 1944) The world is beautiful, and uniformly so, precisely in virtue of its irreducible unity, just as a work of art is said to be beautiful precisely as an integral unity of proportionate parts, that is, as something "more than a mere heap of many parts or existents." (Kovach 1978)

If, as I have argued, there is a cause of the unity of the world - a unifying cause of the world's existence - and the world, in its irreducible unity, reflects a certain degree of beauty, then it would seem to follow that the world was ordained with the intention of reflecting the beauty that it does. The world, in other words, bears the marks of artistic intent, much in the way that the products of human beings are said to be beautiful, precisely as a result of artistic intent. But such intention is quite unintelligible in the absence of a mind. Hence, the principle of unity of the world must be a Mind. Moreover, given that the world is such that there are rational beings capable of aesthetic appreciation, and, given that the world is beautiful such as to be aesthetically appreciated, we may plausibly conclude that the principle of unity of the world is personal.

We may finally note that the argument from the unity of the world to the existence of a transcendent principle of its unity is at once teleological and cosmological. For since every part of the world exists only relative to the other, and the principle of unity of the world is the cause of the ordering of every element towards the greater whole that is the cosmos, then, a fortiori, the principle of unity of the world is also its creator. As the principle of unity 
of the world sustains the world in unity, so too it sustains every part of the world in being, since the being of every part is dependent upon the unity they comprise, and by which they are constituted.

\section{Conclusion}

The argument from the unity of the world to God resembles seeds of argumentation found in Patristic thinkers, such as Tertullian and Athanasius, and it closely resembles a number of arguments from Thomas Aquinas and other scholastic commentators. An intriguing characteristic about this line of argumentation is that it is at once a cosmological and a teleological argument - cosmological, so far as it points to a unifying cause of the world, and teleological, so far as this cause is responsible for the sustaining order and structure of the world. It is my hope and counsel that specialists in the philosophy of religion would take up the task of revisiting a metaphysical argument that has been unjustly neglected. Indeed, as I hope to have shown, the argument from the unity of the world to God is serviced, not weakened, by the latest findings from contemporary science. ${ }^{7}$

\section{References}

Athanasius. On the Incarnation. St. Vladimir's Seminary Press, 2012.

Brentano, Franz. Lectures given at the Universities of Würzburg and Vienna. Springer, 2011.

Cartwright, Nancy. The Dappled World: A Study of the Boundaries of Science. Cambridge University Press, 1999.

Cartwright, Nancy, \& Ward, Keith. Rethinking Order: After the Laws of Nature. Bloomsbury Academic, 2016.

Just Thomism. “Athanasius' Cosmological Argument”. Last Modified September 28, 2013. https://thomism.wordpress.com/2013/09/28/athanasiuss-cosmological-argument

Della Rocca, Michael. “PSR”. Philosophers’ Imprint Vol. 10 No. 7 (2010): 1-13.

7 I am deeply indebted to Stephen Davis and Travis Dumsday for their helpful comments on an earlier draft. 
Feser. Edward. Scholastic Metaphysics: A Contemporary Introduction. Editiones Scholasticae, 2014.

Greco, John, \& Groff, Ruth. Powers and Capacities in Philosophy: The New Aristotelianism. Routledge, 2017.

Koons, Robert C. “God's Existence”. In Neo-Aristotelian Perspectives in Metaphysics, edited by Daniel D. Novotný, \& Lukáš Novák, 263. Routledge, 2016.

Kovach, Francis J. “The Transcendentality of Beauty Revisited”. New Scholasticism Vol 52. No. 3 (1978): 404-412.

Kretzmann, Norman. The Metaphysics of Theism: Aquinas' Natural Theology in Summa Contra Gentiles II. Clarendon Press, 2002.

Marmodoro, Anna. The Metaphysics of Powers: Their Grounding and their Manifestations. Routledge, 2013.

Meyer, Hans. The Philosophy of St. Thomas Aquinas (pp. 299-300). B. Herder book Co, 1944

Molnar, George. Powers: A Study in Metaphysics. Clarendon Press, 2007

Montgomery, G. R.. Leibniz; Discourse on Metaphysics/Correspondence with Arnauld/ Monadology. LaSalle: Open Court, 1980.

Mumford, Stephen, \& Anjum, Rani Lill. Getting Causes From Powers. Oxford University Press, 2015.

Pruss, Alexander R. The Principle of Sufficient Reason: A Reassessment. Cambridge University Press, 2006.

Russell, Bertrand. The Analysis of Matter. Spokesman Books, 2007.

Strawson, Peter Frederick.. Bounds of Sense: An Essay on Kant's Critique of Pure Reason. Routledge, 1975.

Clarke, W. Norris. Explorations in Metaphysics: Being-God-Person. University of Notre Dame Press, 1995.

Clarke, W. Norris. The One and the Many: A Contemporary Thomistic Metaphysics. University of Notre Dame Press, 2001.

Clarke, W. Norris. “System: A New Category of Being?” In The Creative Retrieval of St. Thomas Aquinas: Essays in Thomistic Philosophy New and Old, edited by W. Norris Clarke, 39-47. Fordham University Press, 2009. 